Journal of Mathematics and Statistics 4 (4): 201-207, 2008

ISSN 1549-3644

(C) 2008 Science Publications

\title{
On the Stability and Ultimate Boundedness of Solutions for Certain Third Order Differential Equations
}

\author{
${ }^{1}$ A.T. Ademola and ${ }^{2}$ P.O. Arawomo \\ ${ }^{1}$ Department of Mathematics and Statistics, Bowen University, Iwo, Nigeria \\ ${ }^{2}$ Department of Mathematics, University of Ibadan, Ibadan Nigeria
}

\begin{abstract}
Problem Statement: With respect to our observation in the relevant literature, work on stability and boundedness of solution for certain third order nonlinear differential equations where the nonlinear and the forcing terms depend on certain variables are scare. The objective of this study was to get criteria for stability and boundedness of solutions for these classes of differential equations. Approach: Using Lyapunov second or direct method, a complete Lyapunov function was constructed and used to obtain our results. Results: Conditions were obtained for: (i) Uniform asymptotic stability and, (ii) Uniform ultimate boundedness, of solutions for certain third order non-linear non-autonomous differential equations. Conclusion: Our results do not only bridge the gap but extend some well known results in the literature.
\end{abstract}

Key words: Asymptotic stability, uniform ultimate boundedness; third order; complete Lyapunov function.

\section{INTRODUCTION}

We shall be concerned here, with uniform asymptotic stability of the zero solutions (that is when $\mathrm{p}(\mathrm{t}, \mathrm{x} \mathrm{y}, \mathrm{z}) \mathrm{=}$ ) and uniform ultimate boundedness of solutions of the third order, non-linear, non-autonomous differential equations:

$\dddot{x}+f(t, x, \dot{x}) x+q(t) g(\dot{x})+r(t) h(x)=p(t, x, \dot{x}, \ddot{x})$

On setting $\dot{x}=y, \quad \ddot{x}=z \quad$ Eq. 1 is equivalent to the system of differential equation:

$$
\begin{aligned}
& \dot{x}=y, \dot{y}=z, \\
& \dot{z}=p(t, x, y, z)-f(t, x, y) z-q(t) g(y)-r(t) h(x)
\end{aligned}
$$

In which:

$$
\begin{aligned}
& \mathrm{p}: \mathbb{R}^{+} \times \mathbb{R}^{3} \rightarrow \mathbb{R} ; \mathrm{F}: \mathbb{R}^{+} \times \mathbb{R}^{2} \rightarrow \mathbb{R} ; \mathrm{g}, \mathrm{h}: \mathbb{R} \rightarrow \mathbb{R} ; \mathrm{q}, \mathrm{r}: \mathbb{R}^{+} \rightarrow \mathbb{R} ; \\
& \mathbb{R}=(-\infty, \infty) ; \mathbb{R}^{+}=[0, \infty)
\end{aligned}
$$

$\mathrm{p}, \mathrm{f}, \mathrm{g}, \mathrm{h}, \mathrm{q}$ and $\mathrm{r}$ depend only on the arguments displayed and $\frac{\partial}{\partial t} f(t, x, y)=f_{t}(t, x, y), \frac{\partial}{\partial x} f(t, x, y)=f_{x}(t, x, y), \frac{d}{d x} h(x)=h(x)$ $\frac{\mathrm{d}}{\mathrm{dt}} \mathrm{q}(\mathrm{t})=\mathrm{q}(\mathrm{t})$ and $\frac{\mathrm{d}}{\mathrm{dt}} \mathrm{r}(\mathrm{t})=\mathrm{r}^{\prime}(\mathrm{t})$ exist and are continuous for all $\mathrm{t}, \mathrm{x}$, and $\mathrm{y}$. The dots here as elsewhere, stand for differentiation with respect to the independent variable t. Moreover, the exis tence and uniqueness of solutions of (1) will be assumed. Stability analysis and ultimate boundedness of solutions of nonlinear systems are important area of current research and many concept of stability boundedness of solutions have in the past and also recently been studied, see for instance ${ }^{[14]}$, a survey book, Rouche et al..$^{[15]}$ and Yoshizawa $^{[21,22]}$ are background books. The studies of qualitative behaviour of solutions have been discussed by many authors in a series of research study. See for instance ${ }^{[1-13,16-20]}$ and references therein. These study were done with the aid of Lyapunov functions except in $^{[2,3]}$ where frequency domain approaches were used. With respect to our observation in the relevant literature, these authors considered stability, asymptotic behaviour, boundedness of solutions of Eq. 1, 2 in the case $f(t, x, \dot{x})$ equal any of $f(x, \dot{x}, \ddot{x}), f(x, \dot{x}), f(x)$ and a where $\mathrm{a}$ is positive constant and $\mathrm{q}(\mathrm{t})=\mathrm{r}(\mathrm{t})=1$.

$\mathrm{In}^{[17]}$ Swick discussed conditions for uniform boundedness of Eq. 1 when $p(t, x, \dot{x}, \ddot{x}) \equiv 0$ using an incomplete Lyapunov functions.

Corresponding Author: Ademola, A.T., Department of Mathematics and Statistics, Faculty of Science and Science Education, Bowen University, Iwo, Nigeria, P.M.B. 284, Iwo. Nigeria. Tel. +2348034979685 


\section{MATERIALS AND METHODS}

In this study, conditions for uniform asymptotic stability and uniform ultimate boundedness of solutions of the nonlinear differential Eq. 1 will be considered with the aid of an effective method for studying stability and ultimate boundedness of solutions namely Lyapunov second or direct method. Here a complete Lyapunov function was constructed and used to obtain the following results.

\section{RESULTS}

In the case $\mathrm{p}(\mathrm{t}, \mathrm{x}, \mathrm{y}, \mathrm{z})=0$ (1) and its equivalent system(2) become

$$
\dddot{x}+f(t, x, \dot{x}) \ddot{x}+q(t) g(\dot{x})+r(t) h(x)=0
$$

and

$$
\left\{\begin{array}{l}
\dot{x}=y, \dot{y}=z \\
\dot{z}=-f(t, x, y) z-q(t) g(y)-r(t) h(x)
\end{array}\right.
$$

with the following result

Theorem 1: In addition to the basic assumptions on the functions $\mathrm{f}, \mathrm{g}, \mathrm{h}, \mathrm{q}$ and $\mathrm{r}$, suppose that $\alpha, \alpha_{1}, \mathrm{~b}, \mathrm{~b}_{1}, \mathrm{c}, \mathrm{d}, \mathrm{d}_{1}$, are positive constants and for all $\mathrm{t}=0$

- $\mathrm{h}(0)=0, \frac{\mathrm{h}(\mathrm{x})}{\mathrm{x}} \geq \delta_{0}$ for all $\mathrm{x} ? 0$;

- $\mathrm{h}^{\prime}(\mathrm{x})=\mathrm{c}$ for all $\mathrm{x}$;

- $\mathrm{b} \leq \frac{\mathrm{g}(\mathrm{y})}{\mathrm{y}} \leq \mathrm{b}_{1}$ for all $\mathrm{y} ? 0$;

- $\mathrm{d}_{1}=\mathrm{r}(\mathrm{t})=\mathrm{q}(\mathrm{t}), \mathrm{q}^{\prime}(\mathrm{t})=\mathrm{r}^{\prime}(\mathrm{t})=0$

- $\quad \mathrm{a}=\mathrm{f}(\mathrm{t}, \mathrm{x}, \mathrm{y})=\mathrm{a}_{1}$ for all $\mathrm{x}$ and $\mathrm{y}$

- $\mathrm{yf}_{\mathrm{x}}(\mathrm{t}, \mathrm{x}, \mathrm{y})=0, \mathrm{f}_{\mathrm{t}}(\mathrm{t}, \mathrm{x}, \mathrm{y})=0$ for all $\mathrm{x}$ and $\mathrm{y}$.

Then the zero solution of 4 is uniform asymptotically stable.

In the case $p(t, x, \dot{x}, \ddot{x})=p(t) \neq 0$ Eq. (1) and (2) become

$$
\dddot{x}+f(t, x, \dot{x})+q(t) g(\dot{x})+r(t) h(x)=p(t)
$$

and

$$
\left\{\begin{array}{l}
\dot{\mathrm{x}}=\mathrm{y}, \dot{\mathrm{y}}=\mathrm{z} \\
\dot{\mathrm{z}}=\mathrm{p}(\mathrm{t})-\mathrm{f}(\mathrm{t}, \mathrm{x}, \mathrm{y}) \mathrm{z}-\mathrm{q}(\mathrm{t}) \mathrm{g}(\mathrm{y})-\mathrm{r}(\mathrm{t}) \mathrm{h}(\mathrm{x})
\end{array}\right.
$$

with the following statement:

Theorem 2: Suppose that: (i) hypotheses (i)-(iv) of Theorem 1 hold;

- $|\mathrm{p}(\mathrm{t})| \leq \mathrm{P}_{0}<\infty, \mathrm{P}_{0} \geq 0 \forall \mathrm{t} \geq 0$.

Then the solution $(\mathrm{x}(\mathrm{t}), \mathrm{y}(\mathrm{t}), \mathrm{z}(\mathrm{t}))$ of $(6)$ is uniformly ultimately bounded.

Theorem 3: Suppose that: (i) hypothesis (i) of Theorem 2 holds:

$$
\text { - } \left.|\mathrm{p}(\mathrm{t}, \mathrm{x}, \mathrm{y}, \mathrm{z})| \leq \mathrm{p}_{1}(\mathrm{t})+\mathrm{p}_{2}(\mathrm{t})|\mathrm{x}|+|\mathrm{y}|+|\mathrm{z}|\right)
$$

provided that $|\mathrm{x}|+|\mathrm{y}|+|\mathrm{z}| \geq \mathrm{p}, 0 \leq \mathrm{p}<\infty$, where $\mathrm{p}_{1}(\mathrm{t})$ and $\mathrm{p}_{2}(\mathrm{t})$ are non-negative continuous functions satisfying:

$\mathrm{p}_{1}(\mathrm{t}) \leq \mathrm{P}_{1}, 0 \leq \mathrm{P}_{1}<8, \forall \mathrm{t} \geq 0$

and there is $\in>0$ such that if:

$0 \leq \mathrm{p}_{2}(\mathrm{t}) \leq \in \mathrm{t} \geq 0$

Then the solution $(x(t), y(t), z(t))$ of (2) is uniformly ultimately bounded.

\section{DISCUSSION}

The proofs of Theorem 1, 2 and 3 depend on the continuously differentiable function $\mathrm{V}=\mathrm{V}(\mathrm{t}, \mathrm{x}, \mathrm{y}, \mathrm{z})$ defined by:

$$
\begin{aligned}
2 V= & 2(\alpha+a) r(t) H(x)+4 q(t) G(y)+4 r(t) h(x) y \\
& +2 z^{2}+\beta y^{2}+b \beta x^{2}+2 a \beta x y+2 \beta x z+2(\alpha+a) y z \\
& +2(\alpha+a) \int_{0}^{y} \tau f(t, x, \tau) d \tau
\end{aligned}
$$

where $\alpha$ and $\beta$ are positive constants satisfying:

$$
\frac{\mathrm{c}}{\mathrm{b}}<\alpha<\mathrm{a}
$$

and 


$$
\begin{aligned}
& \mathrm{o}<\beta<\min \left\{\mathrm{b}-\frac{\mathrm{c}}{\mathrm{a}}\right. \\
& \delta_{1}(\mathrm{ab}-\mathrm{c})\left\{\mathrm{a}+1+\delta_{0}^{-1} \delta_{1}^{-1}\left[\mathrm{q}(\mathrm{t}) \frac{\mathrm{g}(\mathrm{y})}{\mathrm{y}}-\mathrm{b}\right]^{2}\right\}^{-1} \\
& (\mathrm{a}-\alpha) 2^{-1}\left[\mathrm{a}+1+\delta_{0}^{-1} \delta_{1}^{-1}[\mathrm{f}(\mathrm{t}, \mathrm{x}, \mathrm{y})-\mathrm{a}]^{2}\right]^{-1}
\end{aligned}
$$

and that:

$$
H(x)=\int_{0}^{x} h(\xi) d \xi \text { and } G(y)=\int_{0}^{y} g(\tau) d \tau
$$

Lemma 1: Subject to conditions (i)-(iv) of Theorem 1, $\mathrm{V}(\mathrm{t}, 0,0,0)=0$ and there exist positive constants

$\mathrm{D}_{0}=\mathrm{D}_{0}\left(\alpha, \mathrm{b}, \mathrm{c}, \mathrm{d}_{0}, \mathrm{~d}_{1} \alpha, \beta\right)$ and $\mathrm{D}_{1}=\mathrm{D}_{1}\left(\alpha, \alpha_{1}, \mathrm{~b}, \mathrm{~b}_{1}, \mathrm{c}, \mathrm{r}_{0}, \mathrm{q}_{\mathrm{o}}\right.$, $\alpha, \beta$ ) such that:

$\mathrm{D}_{0}\left(\mathrm{x}^{2}(\mathrm{t})+\mathrm{y}^{2}(\mathrm{t})+\mathrm{z}^{2}(\mathrm{t})\right)=\mathrm{V}(\mathrm{t})=\mathrm{D}_{1}\left(\mathrm{x}^{2}(\mathrm{t})+\mathrm{y}^{2}(\mathrm{t})+\mathrm{z}^{2}(\mathrm{t})\right)$

Proof: Setting $x(t)=y(t)=z(t)=0$ in $(9)$, clearly $\mathrm{V}(\mathrm{t}, 0,0,0)=0$. Then $(9)$ can be recast in the form:

$2 \mathrm{~V}=\mathrm{V}_{1}+\mathrm{V}_{2}+\mathrm{V}_{3}$

Where

$\mathrm{V}_{1}=2(\alpha+\mathrm{a}) \mathrm{r}(\mathrm{t}) \mathrm{H}(\mathrm{x})+4 \mathrm{q}(\mathrm{t}) \mathrm{G}(\mathrm{y})+4 \mathrm{r}(\mathrm{t}) \mathrm{h}(\mathrm{x}) \mathrm{y}$,

$\mathrm{V}_{2}=\mathrm{b} \beta \mathrm{x}^{2}+\left(\alpha^{2}+\beta\right) \mathrm{y}^{2}+\mathrm{z}^{2}+2 \alpha \beta \mathrm{xy}+2 \beta \mathrm{xz}+2 \mathrm{ayz}$,

and

$$
\begin{aligned}
& \mathrm{V}_{3}=\mathrm{z}^{2}+2 \alpha \mathrm{yz}+\alpha^{2} \mathrm{y}^{2}+2(\alpha+\mathrm{a}) \int_{0}^{\mathrm{y}} \tau \mathrm{f}(\mathrm{t}, \mathrm{x}, \tau) \mathrm{d} \tau \\
& -\left(\alpha^{2}+\mathrm{a}^{2}\right) \mathrm{y}^{2} .
\end{aligned}
$$

In view of hypothesis (iv) of the Theorem $1, \mathrm{r}(\mathrm{t}) \geq \mathrm{d}_{1}$ and $\mathrm{q}(\mathrm{t}) \geq \mathrm{r}(\mathrm{t})$ together imply:

$$
\frac{1}{2} \mathrm{~V}_{1} \geq \delta_{1}[(\alpha+\mathrm{a}) \mathrm{H}(\mathrm{x})+2 \mathrm{G}(\mathrm{y})+2 \mathrm{~h}(\mathrm{x}) \mathrm{y}]
$$

By hypothesis (ii) of Theorem 1, we have:

$$
2 G(y)+2 h(x) y \geq-b^{-1} h(x)
$$

since $b>0$ and $(b y+h(x))^{2} \geq 0$ for all $x$ and $y$. Also from hypotheses (i) and (ii) and the fact that:

$$
h^{2}(x)=2 \int_{0}^{x} h^{\prime}(\xi) h(\xi) d \xi
$$

Since $h(0)=0$, we have:

$$
(\alpha+a) H(x) \geq \frac{1}{2}[(\alpha+\alpha) b-2 c] b^{-1} \delta_{0} x^{2}+b^{-t} h^{2}(x)
$$

On gathering (14a) and (14b) into (13), we obtain:

$V_{1} \geq[(\alpha+a) b-2 c] b^{-1} d_{0} d_{1} x^{2}$

Also $\mathrm{V}_{2}$ can be recast in the form $\mathrm{XPX}^{\mathrm{T}}$, where:

$$
X=(x y z), P=\left(\begin{array}{lcc}
b \beta & \alpha \beta & \beta \\
\alpha \beta & \left(\alpha^{2}+\beta\right) & a \\
\beta & a & 1
\end{array}\right)
$$

and $\mathrm{X}^{\mathrm{T}}$ is the transpose of $\mathrm{X}$. The eigenvalues of matrix $P$ will all be positive, thus det $P=\beta^{2}(b-\beta)>\beta^{2}$ since $b$ $\beta>0$ by (10b), so that:

$\mathrm{V}_{2} \geq B^{2}\left(\mathrm{x}^{2}+\mathrm{y}^{2}+\mathrm{z}^{2}\right)$

Finally, by hypothesis (v) of the theorem $f(t, x, y) \geq$ a for all $x, y$ and $t \geq 0$ then:

$$
\mathrm{V}_{3} \geq \alpha \mathrm{y}^{2}
$$

since $\alpha$-a $>0$ by (10a) and $(z+\alpha y)^{2} \geq 0$ for all y and $z$. A combination of estimates (15a), (15b) and (15c) yields :

$$
\begin{aligned}
& \mathrm{V} \geq \frac{1}{2}\left[[(\alpha+a) b-2 c] b^{-1} \delta_{0} \delta+\frac{1}{2} \beta^{2}\right] x^{2} \\
& +\frac{1}{2}\left(\alpha+\beta^{2}\right) y^{2}+\frac{1}{2} \beta^{2} z^{2} .
\end{aligned}
$$

By (10) $\alpha b-c>0$, ab-c $>0$ and a, b, d $d_{0}, d_{1}, \alpha, \beta$ are all positive constants, there exists a positive constant:

$$
\delta_{2}=\frac{1}{2} \min \left[[(\alpha+a) b-2 c] b^{-1} \delta_{0} \delta_{1}+\frac{1}{2} \beta^{2} ;\left(\alpha+\beta^{2}\right) ; \beta^{2}\right]
$$

such that:

$V \geq d_{2}\left(x^{2}+y^{2}+z^{2}\right)$

for all $x, y, z$ and $\mathrm{t} \geq 0$, this established the lower inequality in (11). To prove the upper inequality in (11), hypotheses (ii) and (iv) of the theorem imply that:

$\mathrm{h}(\mathrm{x}) \leq \mathrm{c} \mathrm{x}$ for all $\mathrm{x} \neq 0$ 
and

$\mathrm{r}(\mathrm{t}) \leq \mathrm{r}_{0}$ and $\mathrm{q}(\mathrm{t}) \leq \mathrm{q}_{0}$ for $\mathrm{t} \geq 0$

where $\mathrm{r}_{0}$ and $\mathrm{q}_{0}$ are positive constants.

From estimates (17a) and (17b), we obtain:

$\mathrm{V}_{1} \leq \frac{1}{2}\left(\alpha+\mathrm{a}+\frac{1}{2}\right) \mathrm{c}_{6} \mathrm{x}^{2}+\left(\mathrm{b}_{1} \mathrm{q}_{0}+\mathrm{cr}_{0}\right) \mathrm{y}^{2}$

where we have used the inequality:

$2|x||y| \leq x^{2}+y^{2}$

Sum of (12c) and (12d) together with the Young's inequality yields:

$\mathrm{V}_{2}+\mathrm{V}_{3} \leq(\mathrm{a}+\mathrm{b}+1) \beta \mathrm{x}^{2}+\left[\beta(\mathrm{a}+1)+(\alpha+\mathrm{a})\left(\mathrm{a}_{1}+1\right)\right] \mathrm{y}^{2}$
$+(\alpha+\beta+\mathrm{a}+2) \mathrm{z}^{2}$

Substituting (18a) and (18b) into (9) to get:

$$
\begin{aligned}
& \mathrm{V} \leq \frac{1}{2}\left[(\mathrm{a}+\mathrm{b}+1)+\frac{1}{2}\left(\alpha+\mathrm{a}+\frac{1}{2}\right) \mathrm{cr}_{0}\right] \mathrm{x}^{2}+\frac{1}{2}\left[(\alpha+\mathrm{a})\left(\mathrm{a}_{1}+1\right)\right. \\
& \left.+\beta(\mathrm{a}+1)+\left(\mathrm{bq}_{0}+\mathrm{cr}_{0}\right)\right] \mathrm{y}^{2}+\frac{1}{2}(\alpha+\beta+\mathrm{a}+2) \mathrm{z}^{2}
\end{aligned}
$$

Since $\mathrm{a}, \mathrm{b}, \mathrm{c}, \mathrm{a}, \mathrm{B}, \mathrm{a}_{1}, \mathrm{~b}_{1}, \mathrm{r}_{0}$ and $\mathrm{q}_{0}$ are positive constants, there exists a positive constant:

$$
\begin{aligned}
& \delta_{3}=\frac{1}{2} \max \left[\left[(a+b+1)+\frac{1}{2}\left(\alpha+a+\frac{1}{2}\right) \mathrm{cr}_{0}\right]\right. \\
& \left.\left[(\alpha+a)\left(a_{1}+1\right)+\beta(a+1)+b_{1} q_{0}+c_{0}\right)\right] \\
& (\alpha+\beta+a+2)]
\end{aligned}
$$

such that:

$$
\mathrm{V} \leq \mathrm{d}_{3}\left(\mathrm{x}^{2}+\mathrm{y}^{2}+\mathrm{z}^{2}\right)
$$

Equation 19 is the upper inequality in (11), and hence estimate (16) clearly implies that $\mathrm{V}(\mathrm{t}, \mathrm{x}, \mathrm{y}, \mathrm{z})$ ? +8 as $\left(x^{2}+y^{2}+z^{2}\right)$ ? 8 . From (16) and (19), Lemma 1 is established.

Lemma 2: Under the hypotheses of Theorem 1, there exists a constant $\mathrm{D}_{3}>0$ depending only on a,b,c, $\mathrm{d}_{0}, \mathrm{~d}_{1}, \alpha$ and $\beta$ such that if $(x(t), y(t), z(t))$ is any solution of (4), then:

$$
\dot{\mathrm{V}} \equiv \frac{\mathrm{d}}{\mathrm{dt}} \mathrm{V}\left(\mathrm{t}, \mathrm{x}(\mathrm{t}), \mathrm{y}(\mathrm{t}), \mathrm{z}(\mathrm{t}) \leq-\mathrm{D}_{3}\left(\mathrm{x}^{2}(\mathrm{t})+\mathrm{y}^{2}(\mathrm{t})+\mathrm{z}^{2}(\mathrm{t})\right)\right.
$$

Proof: Let $(x(t), y(t), z(t))$ be any solution of (4), then an ele mentary calculation of (12), and (4) yields:

$$
\begin{aligned}
& \dot{V}_{(4)}=(\alpha+a) r^{\prime}(t) H(x)+2 q^{\prime}(t) G(y)+2 r^{\prime}(t) y h(x)-\beta r(t) h(x) x \\
& \left.+(\alpha+a) \int_{0}^{y} \tau f_{t}(t, x, \tau) d \tau+\alpha+a\right) y \int_{0}^{y} \tau f_{x}(t, x, \tau) d \tau+a \beta y^{2} \\
& -r(t)\left[(\alpha+a) \frac{q(t) g(y)}{r(t) y}-2 h^{\prime}(x)\right] y^{2}-\beta[f(t, x, y)-a] x z \\
& -[2 f(t, x, y)-(\alpha+a)] z^{2}-\beta\left[\frac{q(t) g(y)}{y}-b\right] x y+2 \beta y z .
\end{aligned}
$$

In view of hypothesis (vi) of Theorem 1,

$$
(\alpha+a)\left[\int_{0}^{y} \tau f_{t}(t, x, \tau) d \tau+y \int_{0}^{y} \tau f_{x}(t, x, \tau) d \tau\right] \leq 0,
$$

for all $\mathrm{x}, \mathrm{y}$ and $\mathrm{t} \geq 0$ since $\alpha$ and a are positive constants and by Young's inequality, we have:

$$
\begin{aligned}
& \dot{\mathrm{V}}_{(4)} \leq \mathrm{W}_{1}-\mathrm{W}_{2}+(\mathrm{a}+1) \beta \mathrm{y}^{2}+\beta \mathrm{z}^{2} \\
& -\beta[\mathrm{f}(\mathrm{t}, \mathrm{x}, \mathrm{y})-\mathrm{a}] \mathrm{xz}-\beta\left[\frac{\mathrm{q}(\mathrm{t}) \mathrm{g}(\mathrm{y})}{\mathrm{y}}-\mathrm{b}\right] \mathrm{xy}
\end{aligned}
$$

Where:

$\mathrm{W}_{1}=(\alpha+\mathrm{a}) \mathrm{r}^{\prime}(\mathrm{t}) \mathrm{H}(\mathrm{x})+2 \mathrm{q}^{\prime}(\mathrm{t}) \mathrm{G}(\mathrm{y})+2 \mathrm{r}^{\prime}(\mathrm{t}) \mathrm{yh}(\mathrm{x})$

and

$$
\begin{aligned}
& W_{2}=\beta r(t) h(x) x+r(t)\left[(\alpha+a) \frac{q(t) g(y)}{r(t) y}-2 h^{\prime}(x)\right] y^{2} \\
& +[2 f(t, x, y)-(\alpha+a)] z^{2}
\end{aligned}
$$

Now if $r^{\prime}(t)=0$ for such $t^{\prime} s$ we have:

$\mathrm{W}_{1}=2 \mathrm{q}^{\prime}(\mathrm{t}) \mathrm{G}(\mathrm{y})$

then by condition (ii) $\mathrm{G}(\mathrm{y}) \geq 0$ for all $\mathrm{y}$ ? 0 , so that $\mathrm{W}_{1} \leq 0$ since $\mathrm{q}^{\prime}(\mathrm{t}) \leq 0$ for all $\mathrm{t} \geq 0$.

If $r^{\prime}(t)<0$, since $q^{\prime}(t) \leq r^{\prime}(t)$ it follows that:

$\mathrm{W}_{1} \leq \mathrm{r}^{\prime}(\mathrm{t})[(\alpha+\mathrm{a}) \mathrm{H}(\mathrm{x})+2 \mathrm{G}(\mathrm{y})+2 \mathrm{yh}(\mathrm{x})]$.

It is clear, from (14a) and (14b) that:

$(\alpha+a) H(x)+2 G(y)+2 y h(x) \geq 0$

for all $\mathrm{x}$ and $\mathrm{y}$, since $\alpha$ and a are positive constants, hence in both cases we have: 
$\mathrm{W}_{1} \leq 0$

Also hypotheses (i) and (iv) of Theorem 1, imply

$\beta r(t) h(x) x \geq \beta d_{0} \beta_{1} x^{2} \forall x \neq 0$

Since $\mathrm{r}(\mathrm{t}) \leq \mathrm{q}(\mathrm{t}), \mathrm{g}(\mathrm{y}) \geq$ by $(\mathrm{y} \neq 0), \mathrm{h}^{\prime}(\mathrm{x}) \leq \mathrm{c} \forall \mathrm{x}$ and $\mathrm{r}(\mathrm{t}) \geq \mathrm{d}_{1} \forall \mathrm{t} \geq 0$, it follows by (10) that:

$r(t)\left[(\alpha+a) \frac{q(t) g(y)}{r(t) y}-2 h^{\prime}(x)\right] \geq \delta_{1}[(\alpha+a) b-2 c]>0$ so that:

By hypothesis $(v) f(t, x, y) \geq$ a for all $x, y$ and $t \geq 0$

$2 f(t, x, y)-(\alpha+a) \geq a-\alpha$

On gathering estimates (23a), (23b) and (23c), we obtain:

$W_{2} \geq \beta d_{0} d_{1} x^{2}+d_{1}[(\alpha+a) b-2 c] y^{2}+(a-\alpha) z^{2}$

From (22) and (24), estimate (21) becomes:

$$
\begin{aligned}
& \dot{\mathrm{V}}_{4} \leq-\beta \delta_{1} \delta_{1} \mathrm{x}^{2}-\delta_{1}(\alpha \mathrm{b}-\mathrm{c}) \mathrm{y}^{2}-\left[\delta_{1}(\mathrm{ab}-\mathrm{c})\right. \\
& -(\mathrm{a}+1) \beta] \mathrm{y}^{2}-\frac{1}{2}(\mathrm{a}-\alpha) \mathrm{z}^{2}-\left[\frac{1}{2}(\mathrm{a}-\alpha)-\beta\right] \mathrm{z}^{2} \\
& \left.-\beta\left[\frac{\mathrm{q}(\mathrm{t}) \mathrm{g}(\mathrm{y})}{\mathrm{y}}-\mathrm{b}\right]\right] \mathrm{xy}-\beta[\mathrm{f}(\mathrm{t}, \mathrm{x}, \mathrm{y})-\mathrm{a}] \mathrm{xz} \\
& \dot{\mathrm{V}}_{4} \leq-\frac{1}{2} \beta \delta_{0} \delta_{1} \mathrm{x}^{2}-\delta_{1}(\alpha \mathrm{b}-\mathrm{c}) \mathrm{y}^{2}-\frac{1}{2}(\mathrm{a}-\alpha) \mathrm{z}^{2} \\
& -\left[\delta_{1}(\mathrm{ab}-\mathrm{c})-\beta\left[\mathrm{a}+1+\delta_{0}^{-1} \delta_{1}^{-1}\left[\frac{\mathrm{q}(\mathrm{t}) \mathrm{g}(\mathrm{y})}{\mathrm{y}}-\mathrm{b}\right]^{2}\right]\right] \mathrm{y}^{2} \\
& -\left[\frac{1}{2}(\mathrm{a}-\alpha)-\beta\left[1+\delta_{0}^{-1} \delta_{1}^{-1}[\mathrm{f}(\mathrm{t}, \mathrm{x}, \mathrm{y})-\mathrm{a}]^{2}\right]\right] \mathrm{z}^{2} \\
& -\frac{1}{4} \beta \delta_{0} \delta_{1}\left[\mathrm{x}+2 \delta_{0}^{-1} \delta_{1}^{-1}\left[\left[\frac{\mathrm{q}(\mathrm{t}) \mathrm{g}(\mathrm{y})}{\mathrm{y}}-\mathrm{b}\right]\right] \mathrm{y}\right]^{2} \\
& -\frac{1}{4} \beta \delta_{0} \delta_{1}\left[\mathrm{x}+2 \delta_{0}^{-1} \delta_{1}^{-1}[\mathrm{f}(\mathrm{t}, \mathrm{x}, \mathrm{y})-\mathrm{a}] \mathrm{z}\right]^{2}
\end{aligned}
$$

Now by (10) and the fact that:

$$
\begin{aligned}
& {\left[\mathrm{x}+2 \delta_{0}^{-1} \delta_{1}^{-1}\left[\frac{\mathrm{q}(\mathrm{t}) \mathrm{g}(\mathrm{y})}{\mathrm{y}}-\mathrm{b}\right] \mathrm{y}\right]^{2} \geq 0} \\
& {\left[\mathrm{x}+2 \delta_{0}^{-1} \delta_{1}^{-1}[\mathrm{f}(\mathrm{t}, \mathrm{x}, \mathrm{y})-\mathrm{a}] \mathrm{z}\right]^{2} \geq 0}
\end{aligned}
$$

for all $\mathrm{x}, \mathrm{y}, \mathrm{z}$ and $\mathrm{t} \geq 0$ and $\beta, \mathrm{d}_{0} \mathrm{~d}_{1}$ are all positive constants, there exists a positive constant:

$\left.\delta_{4}=\min \left[\frac{1}{2} \beta \delta_{0} \delta_{1} ; \delta_{1}(\alpha b-c) ; \frac{1}{2}(a-\alpha)\right]\right]$

such that for all $\mathrm{x}, \mathrm{y}, \mathrm{z}$ and $\mathrm{t} \geq 0$ :

$\dot{\mathrm{V}}_{(4)} \leq-\mathrm{d}_{4}\left(\mathrm{x}^{2}+\mathrm{y}^{2}+\mathrm{z}^{2}\right)$

This completes the proof of Lemma 2.

Proof of Theorem 1: Let $(\mathrm{x}(\mathrm{t}), \mathrm{y}(\mathrm{t}), \mathrm{z}(\mathrm{t}))$ be any solution of (4). To prove the Theorem 1, we shall use the usual limit point argument as is contained in ${ }^{[23]}$ to show that when Lemma 1 and Lemma 2 hold, then $\mathrm{V}(\mathrm{t})$ $\mathrm{V}(\mathrm{t}) \equiv \mathrm{V}(\mathrm{t}, \mathrm{x}(\mathrm{t}), \mathrm{y}(\mathrm{t}), \mathrm{z}(\mathrm{t}) \rightarrow 0$ as $\mathrm{t} \rightarrow 8$. In view of the fact that from Lemma $1 \mathrm{~V}(\mathrm{t}, \mathrm{x}, \mathrm{y}, \mathrm{z})=0$ if and if only if $\mathrm{x}^{2}+\mathrm{y}^{2}+\mathrm{z}^{2}=0, \mathrm{~V}(\mathrm{t}, \mathrm{x}, \mathrm{y}, \mathrm{z})>0$ if and if only if $\mathrm{x}^{2}+\mathrm{y}^{2}+\mathrm{z}^{2} \neq$ $0, \mathrm{~V}(\mathrm{t}, \mathrm{x}, \mathrm{y}, \mathrm{z}) \rightarrow+8$ if and if only if $\mathrm{x}^{2}+\mathrm{y}^{2}+\mathrm{z}^{2} \rightarrow 8$. The remaining of this proof follows the strategy indicated in ${ }^{[11]}$, and hence it omitted. This completes the proof of Theorem 1.

Proof of Theorem 2: Let $(\mathrm{x}(\mathrm{t}), \mathrm{y}(\mathrm{t}), \mathrm{z}(\mathrm{t})$ be any solution of (6). According to Lemma 1 and Lemma 2, it follows that $\mathrm{V}(\mathrm{t}, \mathrm{x}, \mathrm{y}, \mathrm{z})=0$ if and if only if $\mathrm{x}+\mathrm{y}^{2}+\mathrm{z}^{2}=0$, $\mathrm{V}(\mathrm{t}, \mathrm{x}, \mathrm{y}, \mathrm{z})>0$ if and if only if $\mathrm{x}^{2}+\mathrm{y}^{2}+\mathrm{z}^{2} \neq 0$, $\mathrm{V}(\mathrm{t}, \mathrm{x}, \mathrm{y}, \mathrm{z}) \rightarrow+8$ if and if only if $\mathrm{x}^{2}+\mathrm{y}^{2}+\mathrm{z}^{2} \rightarrow 8$. Along any solution $(\mathrm{x}(\mathrm{t}), \mathrm{z}(\mathrm{t}), \mathrm{z}(\mathrm{t}))$ we have:

$$
\left.\dot{\mathrm{V}}_{(6)}=\dot{\mathrm{V}}_{(4)}+\beta \mathrm{x}+(\alpha+\mathrm{a}) \mathrm{y}+2 \mathrm{z}\right] \mathrm{p}(\mathrm{t})
$$

By Lemma 2:

$$
\dot{\mathrm{V}}_{(4)} \leq-\delta_{4}\left(\mathrm{x}^{2}+\mathrm{y}^{2}+\mathrm{z}^{2}\right)
$$

in (25), so that:

$$
\dot{\mathrm{V}}_{(6)} \leq-\delta_{4}\left(\mathrm{x}^{2}+\mathrm{y}^{2}+\mathrm{z}^{2}\right)+3^{1 / 2} \delta_{5} \mathrm{P}\left(\mathrm{x}^{2}+\mathrm{y}^{2}+\mathrm{z}^{2}\right)^{1 / 2}
$$

where $\mathrm{d}_{5}=\max [\beta ; \alpha+\mathrm{a} ; 2]$. Choose:

$$
\left(\mathrm{x}^{2}+\mathrm{y}^{2}+\mathrm{z}^{2}\right)^{\frac{1}{2}} \geq 2 \sqrt{3} \delta_{5} \delta_{4}^{-1}=\delta_{6}
$$

the inequality in (26) becomes:

$$
\dot{\mathrm{V}}_{(6)} \leq-\frac{1}{2} \delta_{4}\left(\mathrm{x}^{2}+\mathrm{y}^{2}+\mathrm{z}^{2}\right) \leq-\delta_{7}
$$


provided that:

$$
\mathrm{x}^{2}+\mathrm{y}^{2}+\mathrm{z}^{2} \geq 2 \delta_{7} \delta_{4}^{-1}=\delta_{8}
$$

Theorem 2 follows from (16), (19) and (27), see for instance ${ }^{[22]}$.

Proof of Theorem 3: Along any solution $(\mathrm{x}(\mathrm{t}), \mathrm{y}(\mathrm{t})$, $\mathrm{z}(\mathrm{t}))$ we have:

$$
\dot{\mathrm{V}}_{(2)}=\dot{\mathrm{V}}_{(4)}+[\beta \mathrm{x}+(\alpha+\mathrm{a}) \mathrm{y}+2 \mathrm{z}] \mathrm{p}(\mathrm{t}, \mathrm{x}, \mathrm{y}, \mathrm{z})
$$

By Lemma 2, $\dot{\mathrm{V}}_{(4)} \leq-\delta_{4}\left(\mathrm{x}^{2}+\mathrm{y}^{2}+\mathrm{z}^{2}\right)$ in $(25)$, and by condition (ii) of Theorem 3, we have:

$$
\begin{aligned}
& \dot{\mathrm{V}}_{(2)} \leq \dot{\mathrm{V}}_{(4)}+\delta_{5}\left(|\mathrm{x}|+|\mathrm{y}|+|\mathrm{z}|\left[\mathrm{p}_{1}(\mathrm{t})+\mathrm{p}_{2}(\mathrm{t})|\mathrm{x}|+|\mathrm{y}|+|\mathrm{z}|\right)\right] \\
& \leq-\left(\delta-3 \delta_{5} \in\right)\left(\mathrm{x}^{2}+\mathrm{y}^{2}+\mathrm{z}^{2}\right)+3^{1 / 2} \delta_{5}\left(\mathrm{x}^{2}+\mathrm{y}^{2}+\mathrm{z}^{2}\right)^{/ 2}
\end{aligned}
$$

Choose $\in$ so small so that $\mathrm{d}_{4}>3 \mathrm{~d}_{5} \in$, there exist positive constants $d_{9}$ and $d_{10}$ such that:

$$
\dot{\mathrm{V}}_{(2)} \leq-\delta_{9}\left(\mathrm{x}_{2}+\mathrm{y}^{2}+\mathrm{z}^{2}\right)+\delta_{10}\left(\mathrm{x}^{2}+\mathrm{y}^{2}+\mathrm{z}^{2}\right)^{1 / 2}
$$

The remaining of this proof follows the strategy indicated in the proof of Theorem 2. Hence it is omitted; this completes the proof of Theorem 3.

Remark 1: If $\mathrm{p}(\mathrm{t}, \mathrm{x}, \mathrm{y}, \mathrm{z})=\mathrm{e}(\mathrm{t})$ then (1) reduces to the case studied by Swick ${ }^{[17]}$. Clearly our results improve and extend that of ${ }^{[17]}$.

Remark 2: Unlike in ${ }^{[17]}$ and ${ }^{[21]}$, the bounding constants in Theorem 2 and Theorem 3 do not depend on the solutions of (1) and (5).

\section{CONCLUSION}

It is well known that the problem of ultimate boundedness of solutions of nonlinear is very important in the theory and applications of differential equations. And the effective method for studying problems of ultimate boundedness of solution of nonlinear differential equations is still the Lyapunov's direct method see for instance ${ }^{[1,7-15,18-23]}$. In this study a complete Lyapunov function was used to achieve the desired results.

\section{REFERENCES}

1. Ademola, A.T., R Kehinde and M.O. Ogunlaran, 2008. A Boundedness Theorem for a Certain Third Order Nonlinear Differential Equation. J. Math. Stat., 4: 88-93. http://www.scipub.org/fulltext/ jms2/jms24288-93.
2. Afuwape, A.U., 2006. Remarks on BarbashinEzeilo problem on third order nonlinear differential equations. J. Math. Anal. Appl., 317: 613-619. DOI: MR2209582 (2006j:34104).

3. Afuwape, A.U. and O.A. Adesina, 2005. On the bounds for mean-values of solutions to certain third order nonlinear differential equations. Fasciculi Mathematician, 36: 5-14. DOI: MR2223637 (2007a:34054).

4. Andres, J., 1986. Boundedness results for solutions of the equation $\dddot{x}+a \ddot{x}+g(x) \dot{x}+h(x)=p(t)$ without the hypothesis $h(x) \operatorname{sgn} x \geq 0$ for $|x|>R$. Atti. Accad. Naz. Lincei Rend. Cl. Sci. Fis. Mat. Natur., 80: 533-539. DOI: MR0976947(89m:34043).

5. Bereketoglu, H. and Györi, I.; 1997. On the boundedness of solutions of a third order nonlinear differential equation. Dynam. Syst. Appli., 6: 263-270. DOI: MR1461442(98g:34064).

6. Chukwu, E.N., 1975. On boundedness of solutions of third order differential equations. Ann. Mat. Pura. Appl., 104: 123-149. http://www.springer. com/math/journal/10231/104/4/123.

7. Ezeilo, J.O.C., 1961. A note on a boundedness theorem for some third order differential equations. J. London Math. Soc., 36: 439-444. jlms. oxfordjournals.org/content/vols1-/issue1/index.dtl

8. Ezeilo, J.O.C., 963. An elementary proof of a boundedness theorem for a certain third order differential equation. J. London Math. Soc., 38: 11-16. jlms.oxfordjournals.org/content/vols 138/issue 1/index.dtl

9. Ezeilo, J.O.C., 1963. Further results for a solutions of a third order differential equation. Proc. Camb. Phil. Soc., 59: 111-116. DOI: 10.1017/S030500410000205X.

10. Ezeilo, J.O.C. 1963. A boundedness theorem for a certain third order differential equation. Proc. London Math. Soc., 3: 99-124. DOI:10.1112/plms/ s3-13.1.99.

11. Ezeilo, J.O.C., 1968. On the stability of solutions of some third order differential equations. J. London Math. Soc., 43: 161-167. jlms. oxfordjournals.org/content/vols143/issue1/index.dtl.

12. Ezeilo, J.O.C. and H.O. Tejumola, 1973. Boundedness theorems for certain third order differential equations. Atti. Accad. Naz. Lincei Rend. Cl. Sci. Fis. Mat. Natur., 55: 194-201. DOI: MR0364784 (51 \#1038).

13. Hara, T., 1981. On the uniform ultimate boundedness of solutions of certain third order differential equations. J. Math. Anal. Appl., 80: 533-544. DOI: MR0614848 (82f:34062). 
14. Omeike, M.O., 2008. New result in the ultimate boundedness of solutions of a third-order nonlinear ordinary differential equation. J. Inequal. Pure Appl. Math., 9: 15-18. http://jipam.vu.edu.au/ issues.php?op=view issue $\&$ issue $=96$

15. Reissig, R., G. Sansone and R. Conti, 1974. Nonlinear differential equations of higher order. Noordhoff International Publishing Leyeden, pp: 264-286. ISBN: 9001752705.

16. Rouche, N., N. Habets and M. Laloy, 1977. Stability Theory by Liapunov's Direct Method. Applied Math. 22. http://catalog.kfupm.edu.sa/S/Stability_theory_by_ Li.html.

17. Swick, K., 1969. On the boundedness and stability of solutions for some non-autonomous differential equations of the third order. J. London Math. Soc., 44: 347-359. jlms.oxfordjournals.org/content/vols 1-44/issue 1 /index.dtl.

18. Swick, K.E.; 1974. Boundedness and stability for a nonlinear third order differential equation. Atti. Accad. Naz. Lincei Rend. Cl. Sci. Fis. Mat. Natur., 56: 859-865. http://www.lincei.it/
19. Tejumola, H.O., 1970. A note on the boundedness of solutions of some non linear differential equations of the third order. Ghana J. Sci., 11: 117-118. http://www.ghanascience.org /11/2 /117

20. Tejumola, H.O.; 1972. A note on the boundedness and the stability of solutions of certain third order differential equations. Ann. Math. Pura. Appl., 92: 65-75. DOI: 10.1007/BF02417936

21. Tunç, C., 2005. Bounded ness of solutions of a third order nonlinear differential equation. J. Inequal. Pure and Appl. Math., 6: 16. DOI: MR2122950 (2005i:34044).

22. Yoshizawa, T., 1966. Stability theory by Liapunov's second method. The Mathematical Society of Japan, pp: 27-38.

23. Yoshizawa, T., 1975. Stability Theory and Existence of Periodic Solutions and Almost Periodic Solutions. Spriger-Verlag, New York, Heidelberg, Berlin, pp: 40-60. 